\title{
Teaching Reform Research of Structural Mechanics Based on Application-oriented Excellent Engineer Education Training Plan
}

\author{
Chuanteng Huang ${ }^{*}$, Feiqiao Xiong, Shuang Pu \\ School of Engineering and Technology \\ Zunyi Normal College \\ Zunyi, China \\ huangct@yeah.net, 809863983@qq.com,pushuangss@yeah.net
}

\begin{abstract}
This paper aims to discuss the teaching reform of higher engineering education. Based on the standard of Excellent Engineer Education Training Plan, this paper studies the teaching methods of Structural Mechanics, emphasizes the status and effect of the Structural Mechanics in the course system of Civil Engineering, points out the misunderstanding and deficiencies in the course teaching of engineering mechanics. Combining with higher education theory and teaching practice, this paper emphasizes the engineering education should integrate mechanics theory with engineering practice and presents eight recommendations for the application-oriented Structural Mechanics teaching reform. This paper is the exploration of the improvement of higher education quality and reformation of undergraduate teaching.
\end{abstract}

Keywords-Structural Mechanics; teaching reform; teaching method; Application-oriented; Excellent Engineer Education Training Plan

\section{INTRODUCTION}

The Excellent Engineer Education Training Plan (EEETP for short) is a major reform put forward by the Ministry of Education of China to promote and reform the engineering education. The purpose is to train innovative and creative talents to meet the needs of economic and social development under the new situation [1].

At present, what the Civil Engineering need most is the management personnel (i. e., application-oriented personnel), accounting for more than 60\%, for the Guizhou Province, the proportion is even higher, even above $80 \%$. Regional and social requirements are the basis for local undergraduate education, the undergraduates who are qualified for the engineering management and engineering technology will become the mainstream of market demand. In order to meet the concept of engineering education that is "industrial-oriented, local region-oriented and application-oriented", and also to enable students of Civil Engineering in our college to adapt to

This research was financially supported by the Doctoral Program Foundation of Zunyi Normal College (BS [2015]17\#), Youth Scientific Talents Project of Education Department of Guizhou Province of China (Qian Jiao He KY Zi [2016] 257), United Foundation of Science and Technology Department of Guizhou Province of China (Qian Ke He LH Zi [2017] 7083), Cooperative Education Project of Ministry of Education of China (No 201701074015, No. 201701061006) and the Excellent Talent Education Training Program of Education Department of Guizhou Province of China. the development and needs of the industry, our college has set up the EEETP focusing on the application-oriented civil engineers.

In this paper, the course of Structural Mechanics is regarded as the entry point to demonstrate the deficiencies in the mechanics course teaching. According to the training standards of application-oriented civil engineers, combined with higher education theory and teaching practice, eight reform measures are put forward. This paper is a probe about the quality improvement of higher engineering education and the teaching reform of the undergraduate.

\section{THE CURRENT SITUATION OF CIVIL ENGINEERING IN GUIZHOU PROVINCE}

The Civil Engineering is an important part of the secondary industry. It plays a very important role in absorbing the rural population to transfer employment, promoting the income growth of farmers, promoting the development of related industries, expanding the investment in fixed assets, and increasing the local financial revenue.

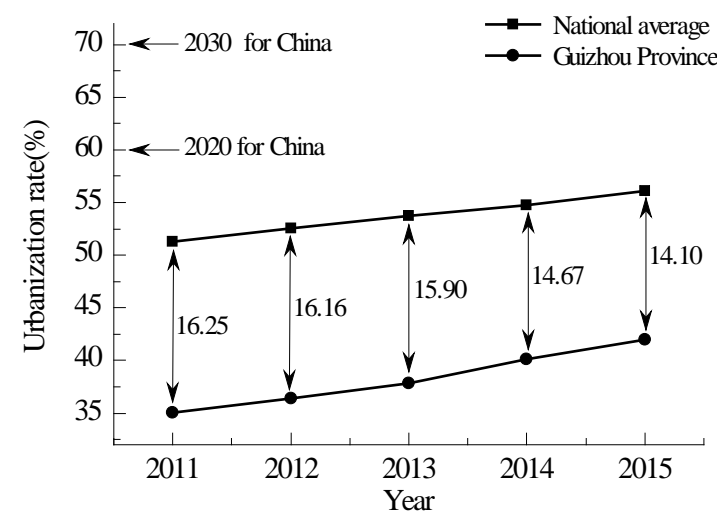

Fig. 1. A comparison of the urbanization rate of the permanent residents between Guizhou and national average during the 12th Five-year Plan period

According to the data and reports of the Housing and Urban-Rural Development Bureau of Guizhou, the Statistical 
Bureau of Guizhou and the National Bureau of Statistics of China, Figure 1 shows comparison of the Urbanization Rate of the Permanent Residents (URPR) between Guizhou Province and the national average during the 12th Five-year Plan period, despite the gradual narrowing of the gap, Guizhou lags behind the national average about 15\%. Table 1 shows URPR of China's western provinces during the 12th Five-year Plan period, and Guizhou Province is at a relatively backward level.

TABLE I. URBANIZATION RATE OF THE PERMANENT RESIDENTS OF CHINA'S WESTERN PROVINCES DURING THE 12TH FIVE-YEAR PLAN PERIOD (\%)

\begin{tabular}{|c|c|c|c|c|c|}
\hline Province & 2011 & 2012 & 2013 & 2014 & 2015 \\
\hline CQ & 55.02 & 56.98 & 58.34 & 59.6 & 60.94 \\
\hline NM & 56.62 & 57.74 & 58.71 & 59.51 & 60.3 \\
\hline NX & 49.82 & 50.67 & 52.01 & 53.61 & 55.2 \\
\hline SN & 47.3 & 50.02 & 51.31 & 52.57 & 53.9 \\
\hline $\mathrm{QH}$ & 46.22 & 47.44 & 48.51 & 49.78 & 50.3 \\
\hline XJ & 43.54 & 43.98 & 44.47 & 46.07 & 47.8 \\
\hline SC & 41.83 & 43.53 & 44.9 & 46.3 & 47.7 \\
\hline GX & 41.8 & 43.53 & 44.81 & 46.01 & 47.06 \\
\hline YN & 36.8 & 39.31 & 40.48 & 41.73 & 43.3 \\
\hline GS & 37.15 & 38.75 & 40.13 & 41.68 & 43.19 \\
\hline GZ & 34.96 & 36.41 & 37.83 & 40.01 & 42.01 \\
\hline $\mathrm{XZ}$ & 22.71 & 22.75 & 23.71 & 25.75 & 27.74 \\
\hline
\end{tabular}

In general, the URPR in Guizhou is relatively low either compared with national average or other provinces in the west, but it shows that Guizhou still has a large space for development and the huge space also means that the development of Civil Engineering is at its best period. At the same time, the higher education of Civil Engineering education in Guizhou should keep pace with the times.

\section{The Role And Function OF StRUCTURAL MECHANICS IN CIVIL ENGINEERING COURSE SYSTEM}

Structural Mechanics is a branch of solid mechanics. It mainly studies the response of the member structure under load and non-load factors: internal forces, reaction forces and displacements, as well as the reasonable compositional rules of structures, structure dynamic characteristics and structural stability.

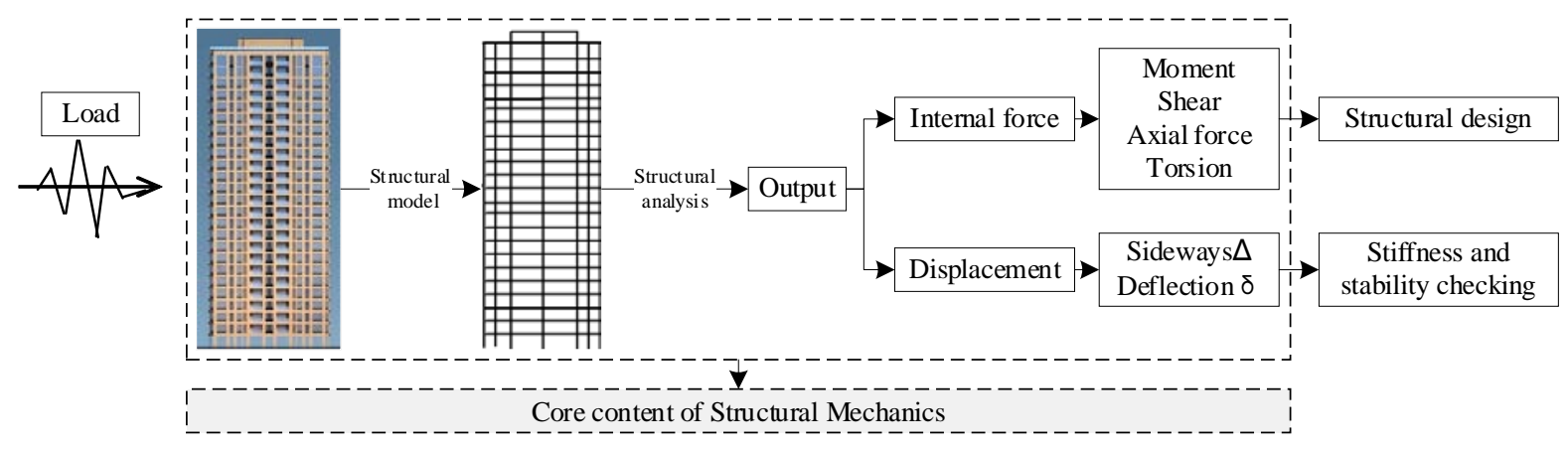

Fig. 2. The Role and function of Structural Mechanics in Civil Engineering course system

As shown in Figure 2, Structural Mechanics is an important basic course in Civil Engineering and related majors. It is not only the development and deepening of math course group (advanced mathematics, college physics) and mechanics course group (material mechanics and theoretical mechanics), but also the foundation of the specialized courses. Structural Mechanics occupies an important position in the entire Civil Engineering course system [2]. And Structural Mechanics is also the professional courses in graduate entrance exam of Civil Engineering in China.

\section{EXISTING PROBLEMS IN THE COURSE TEACHING OF STRUCTURAL MECHANICS}

As mentioned above, Structural Mechanics plays an important role in Civil Engineering; however, there are some aspects that can be improved in the teaching of Structural Mechanics, shown as follows:

- The traditional teaching of Structural Mechanics only focused on theoretical knowledge, overemphasizing the quantitative analysis. With lack of conceptual analysis and engineering thinking, this traditional teaching method cannot accommodate the needs of applicationoriented engineer education;

- The traditional teaching cannot combine mechanics theory with engineering practice;

- Excess pursuit the quantitative calculation method, however, fail to expound the status and function of Structural Mechanics in Civil Engineering curriculum system macroscopically and worse still cut off the 
connection between Structural Mechanics and upstream and downstream courses.

\section{THE MAIN CONTENT OF TEACHING REFORM OF STRUCTURAL MECHANICS}

\section{A. Emphasis on the introduction class}

Introduction class is the beginning of Structural Mechanics, describes the subject, the research content, the research purpose, the research method and the research significance of this course, as well as the difference and connection between this course and other courses, and also needs to clarify the role and status of this course in the entire Civil Engineering course system (shown as in Figure 2). At the same time, students should be taught about the learning methods, teaching arrangements (as shown in Figure 3) and assessment standards, as well as to arouse the students' interest and enthusiasm in learning [3, 4]. Therefore, the authors believe that the introduction class is not only the key point of the entire course, but also the difficulty point of the entire course.

\section{B. Combined with engineering practice case to strengthen the Conceptual Structural Mechanics education}

The perceptibility of Structural Mechanics comes from the diversity of its research objects, the systematisms of its research contents, the logic of its research methods, the flexibility of its solving problems and its practicality close to engineering [5]. Therefore, the guiding ideology of Structural Mechanics teaching is to strengthen the Conceptual Structural Mechanics education, to pay attention to the qualitative structure analysis, and to link theory with practice. The teaching reform of Structural Mechanics include:

- Knowledge of Structural Mechanics should be visualized, interesting and perceptual. Combining the main concepts in the textbook of traditional Structural Mechanics with practice case in real life (as shown in Table 2), to help students understand abstract computational models and concepts.

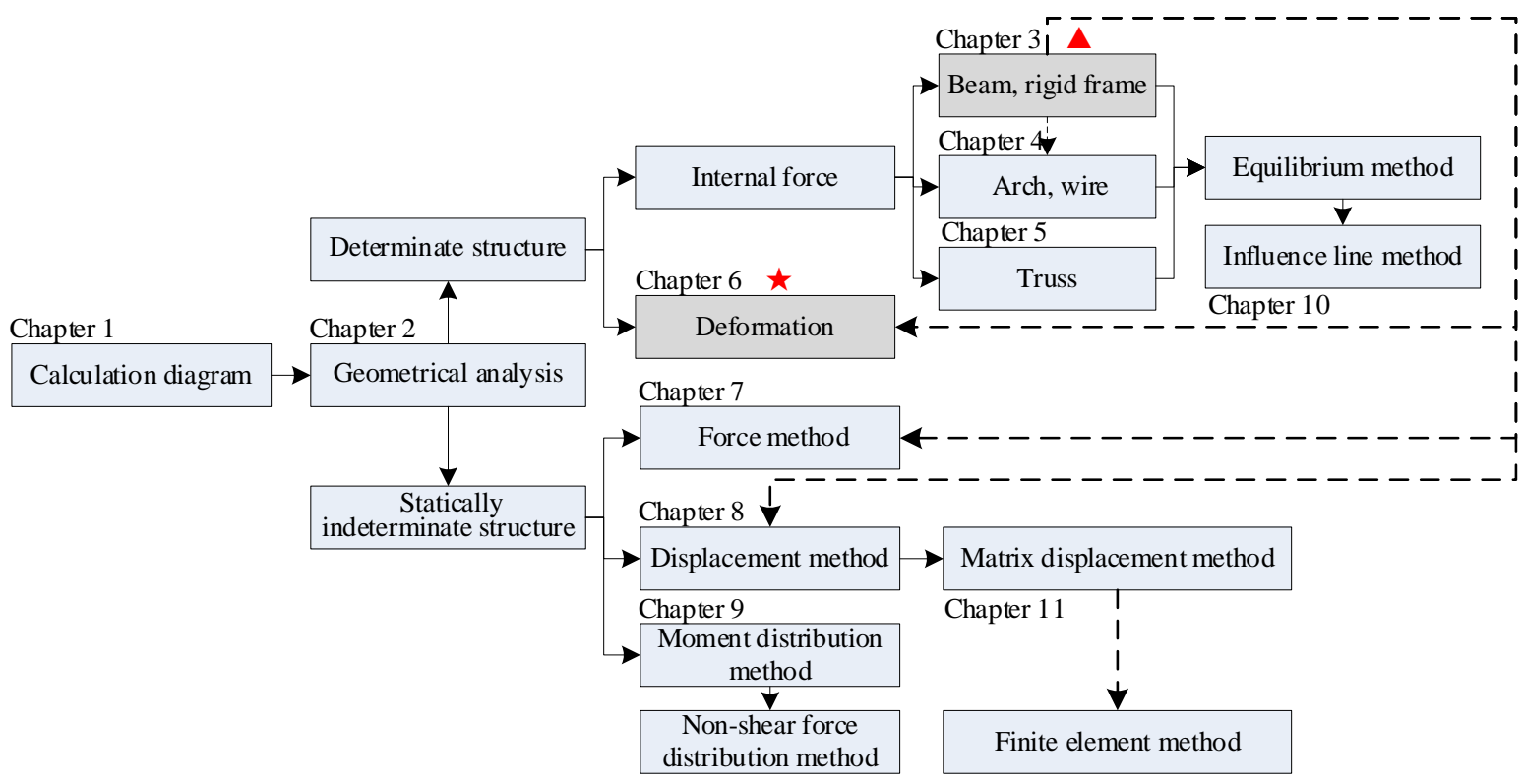

Fig. 3. The main contents of Structural Mechanics and chapter relations (take the contents in reference [6] as an example)

TABLE II. THE VISUALIZED, INTERESTING AND PERCEPTUAL CASE IN REAL LIFE CORRESPONDING TO THE STRUCTURAL MECHANICS

\begin{tabular}{|c|c|}
\hline Content of course & Relevant cases in real life \\
\hline Chapter 1: Introduction and calculation diagram & Flagpoles, horizontal bars, diving board, soccer goal \\
\hline Chapter 2: Geometrical analysis & $\begin{array}{l}\text { Hammer balancing experiment, cantilever platform awning } \\
\text { Superposition method for determining the static bending moment the }\end{array}$ \\
\hline Chapter 3: Beam, rigid frame & $\begin{array}{l}\text { balance method for rigid frame bending moment, the analogy law of the } \\
\text { flexible rope to the shape of the moment diagram }\end{array}$ \\
\hline Chapter 4: Arch, wire & Akashi-Kaikyo Bridge, Golden Gate Bridge, The Zhaozhou Bridge \\
\hline Chapter 5: Truss & Plant, exhibition hall, gymnasium and bridge \\
\hline Chapter 6: Deformation & Horizontal bar and virtual work principle \\
\hline Chapter 7: Force method & Cantilever platform awning with supporting column \\
\hline Chapter 8: Displacement method & Frame structure and framed bent \\
\hline Chapter 9: Moment distribution method & $\begin{array}{l}\text { Rotation stiffness and transfer coefficient, the bottom shear method, anti- } \\
\text { bending point method, distribution of earthquake load }\end{array}$ \\
\hline Chapter 11: Influence line method & Kinematic method, envelope diagram \\
\hline
\end{tabular}




\section{Emphasizing the engineering background of theoretical knowledge}

The concepts, principles and simplified structure in Structural Mechanics have their profound engineering background. Based on the knowledge points and basic mechanics concepts in each chapter, through multimedia information technologies such as pictures, videos, animations and dynamic graph, the contents and corresponding engineering tasks are presented so as to fully stimulate students' motivation and it is more likely to help students establishing the engineering thinking.

\section{Making focus on emotion and values education}

Emotional and values education is an important part of higher education. In the geometric composition analysis course, the teacher should tell students that no matter as big as a country or as small as a person cannot lack the necessary constraints, otherwise it will be in an unstable state or even collapse. In explaining the difference between determinate structure and statically indeterminate structure, there should encourage students developing their interests and hobbies to build themselves into a "statically indeterminate" structure that enhancing their ability to withstand and deal with stress.

\section{E. Promoting the interaction between teacher and students during course}

The concept, theory and computing method in Structural Mechanics are manifold, and the analysis object comes from the highly abstract simplified structure, all these make the calculation complicated and tedious. It is difficult for students to maintain their interest in learning. Comprehensive use of multimedia courseware, teaching experiments, teaching wall charts to promote the interaction between teacher and students during course. So as to improve the teaching performance.

\section{F. Making the determinate structure as the core of the course}

As shown in Figure 3, the calculation of internal force of determinate structure is the basis of displacement calculation and internal force calculation of statically indeterminate structure. Therefore, this part is the core of the whole course. The degrees of mastery of this part directly affect the effectiveness of the entire course learning. Thus, the students should attach great importance to the calculation of the internal force of determinate structure and strengthen the training of three basic methods to improve their ability and to lay a solid foundation for the study of the following chapters.

\section{G. Developing the major competition}

In order to improve the comprehension, application and engineering practice ability, the practical training such as structural design contest and bending moment diagram competition are introduced in extra-curricular teaching $[7,8]$.
These competitions will help students keeping enthusiasm for learning and encouraging students’ passion.

\section{$H$. Improving the examination and evaluation system}

In the new evaluation system of the Structural Mechanics course, the degree of participation in the classroom study, attendance, bending moment map contest, structural design contest, etc. [9]. are all considered and dividing the final test scores into two phases: the mid-term and the finals: Course Final scores $=30 \% \times$ mid-term $+60 \% \times$ final test $+10 \% \times$ (homework + classroom performance) + bonus (1st, 2nd and 3rd place in structural design competition and bending moment diagram contest will plus 5 points, 3 points, 2 points on the final scores, respectively).

\section{SUMMARY}

Teaching reform is not abstract, nor a random attempt. Educational reform should follow the basic educational theory and psychological cognition of the students. In this paper, the teaching reform research of Structural Mechanics based on application-oriented EEETP is discussed, and eight reform recommendations were proposed. In the future, the authors will apply these concepts in the whole class and the entire mechanics course group to promote discipline construction and the EEETP.

\section{REFERENCES}

[1] The Ministry of Education, Several Opinions of the Ministry of Education on Implementing the Excellent Engineer Education Training Plan [EB/OL]. Ministry of Education of the People's Republic of China. 2011-01-08. http://moe.edu.cn/. (In Chinese)

[2] Maiorana C, Sgarbossa L, Salomoni V. New methodologies in teaching e - structural mechanics using WWW[J]. Computer Applications in Engineering Education, 2008, 16(3): 189-210.

[3] Tang W, Li C, Liang Z Q. The importance of introduction class to basic courses in colleges and teaching practice[J]. China Adult Education, 2008 (12): 124-125. (In Chinese)

[4] Yang Z J, Yang X D. Reflections on introduction class in colleges and universities[J]. China University Teaching, 2011, 12: 39-41. (In Chinese)

[5] Zhou Z, Lu J Y, Yi L F, Miu Z W. Teaching reform and practice of structural mechanicstowards eminent civil engineer training[J]. Journal of Architectural Education in Institutions of Higher Learning, 2012, 21(4): 74-77. (In Chinese)

[6] Xiao Y W, Zhang L Y. Structural Mechanics[M]. Beijing: Chian Machine Press, 2013. (In Chinese)

[7] Qu S Y, Hu T, Wu J L, et al. Experimental Teaching Centre Platform" New Engineering" Practice Teaching Mode[J]. EURASIA JOURNAL OF MATHEMATICS SCIENCE AND TECHNOLOGY EDUCATION, 2017, 13(7): 4271-4279

[8] Tsutsui W, Loui M C. The Effectiveness of Weekly Supervised Homework Sessions in an Aerospace Structural Mechanics Course[C]//ASEE 2016 Annual Conference \& Exposition, New Orleans, LA. 2016.

[9] Phillips A T M. Engineering Education, Research, and Design: Breaking In and Out of Liminal Space[J]. Journal of Professional Issues in Engineering Education and Practice, 2017, 143(4): 02517002. 